\title{
Analysis of National Surveillance of Respiratory Pathogen for Children and Adolescents' Community Acquired Pneumonia
}

Eui jeong Roh

Chungnam National University Hospital

Mi-Hee Lee

Incheon Medical Center

JeeYoung Lee

Hallym University Hospital

Hyobin Kim

Inje Sanggye Baek Hospital

Youngmin Ahn

Eulji University Hospital

Ja Koung Kim

Kangwon University hospital

Hyoung young Kim

Pusan University Yangsan Hospital

Min Ji Kim

Sejong Chungnam University Hospital

Eun Kyoung Kang

Dongkuk University Ilsan Hospital

Eun-Ae Yang

Daejeon's Saint Mary's Hospital

Su Jin Lee

Eulji University Daejeon Hospital

Yang Park

Wonkwang University Sanbon Hospital

Ju Hee Seo

Dankook University Hospital

En Lee

Cheonnam National University Hostpial

En Seok Yang

Chosun University Hostpial

Hyung Min Cho

Jesushospital, Jeonju, Republic of Korea

Mi Yong Shin

Soonchunhyang University Bucheon Hospital

Hae Lee Chung

Daegu Catholic University Hospital

Yoon Young Jang

Daegu Catholic University Hospital

Bong Seok Choi

Kyungpook National University Hostpial

Jin A Jung

Dong A University Hospital

Seung Taek You

Wonkwang University Hospital

Myoung Soon Sung

Soonchunhyang University Hospital

Jin Taek Kim

Uijeongbu Saint Mary's Hospital

Bong Seong Kim

Ganneung Asan Hostpital

Yoon ha Whang 
Pusan ST. Mary's Hospital

Jung Yeon Shim

Kangbuk Samsung Hospital

Hyun Jong Yang

Soonchunhyang University Hospital

Man Yong Han

Bundang CHA Medical Center

Hae Young Yew

kogel hospital

\section{Dong Hyuk Kim}

Korea Center For Disease and Prevention

\section{Sangun Jeong}

Korea Center For Disease and Prevention

Kyu Jam Whang

Korea Center For Disease and Prevention

Eun Sil Lee

Chungnam National University Hospital

Eun hee Chung ( $\nabla$ ehchung@cnu.ac.kr)

Chungnam National University Hospital

\section{Research Article}

Keywords: pneumonia, child, surveillance, epidemiology

Posted Date: June 8th, 2021

DOl: https://doi.org/10.21203/rs.3.rs-540764/v1

License: (c) (1) This work is licensed under a Creative Commons Attribution 4.0 International License. Read Full License

Version of Record: A version of this preprint was published at BMC Infectious Diseases on April 4th, 2022. See the published version at https://doi.org/10.1186/s12879-022-07263-z. 


\section{Abstract}

Background: Respiratory infection in particular community acquired pneumonia (CAP) in children is a major disease that ranks high in outpatient and inpatient cases. The causes of CAP vary depending on the individual susceptibility, epidemiological characteristics of the community, and season. We performed this study to establish nationwide surveillance network system and identify the causative agents for CAP and antibiotics resistance in Korean children with CAP..

Methods: The monitoring network was composed of the 28 secondary and tertiary medical institutions. Upper and lower respiratory samples were assayed using culture or Polymerase chaini reaction (PCR) from Aug 2018 to May 2020.

Results: A total of 1023 cases were registered in patients with CAP, and 264 cases (25.8\%) were isolated by culture, S. aureus 131 cases (12.8\%), $S$. pneumoniae 92 cases (9\%), H. influenzae 20 cases (2\%). PCR of atypical pneumonia pathogen revealed 422 cases of M. pneumoniae (41.3\%). Respiratory virus showed positive rates in $65.7 \%$ by multiplex PCR test and of them, human rhinovirus was most highest with 312 cases (30.5\%). The proportion of mixed infection was $49.2 \%$. The rate of antibiotics resistance showed similar results as previous reports.

Conclusions: It will identify the pathogens that cause respiratory infections, and analyze the current status of antibiotic resistance to provide scientific evidence for management policies of domestic respiratory infection. Also, in preparation for the new epidemic, including COVID19, monitoring of respiratory infections in children and adolescents, has become more important, and research should be continuously conducted in the future.

\section{Background}

Pneumonia is an infection of the lower airways and community-acquired pneumonia (CAP) specifically refers to clinical signs and symptoms of pneumonia acquired outside a hospital setting. ${ }^{1}$ In the United States, CAP is the most common causes for hospitalization, with annual incidence of 15.7-22.5 hospitalizations per 100,000 children. ${ }^{2,3}$ According to a 17-year press release (Ministry of Health and Welfare) in Korea, half (44.6\%) of the 1.59 million pneumonia patients in 2015 were reported to be children under the age of ten. ${ }^{4}$

According to statistics from the Health Insurance Review and Assessment Service in 2018, children under the age of 10 have respiratory system diseases, which are the major diseases at the top of outpatient and hospitalization, with pneumonia ranked second in the number of patients by inpatient disease. ${ }^{5}$ These respiratory diseases are mainly caused by bacterial or viral infections and treatments should be selected depending on the pathogen that causes them. However, clinical symptoms alone cannot distinguish the pathogens, so they should be checked through laboratory tests. In most CAP, empirical treatment is provided in that the causes of pneumonia vary widely depending on individual sensitivity, dynamics of the community, seasons. And it is difficult to obtain samples for microbiological diagnosis. Thus, epidemiological data on clinical patterns and causes of childhood pneumonia will help care, including determining the direction of treatment. ${ }^{6}$

The development of Hemophilus influenzae type B (Hib) vaccine and protein binding pneumococcal conjugate vaccine (PCV) have rapidly decreased the frequency of $\mathrm{H}$. influenzae pneumonia and $S$. pneumoniae pneumonia. ${ }^{7}$ Data on changes in serologic type of $S$. pneumoniae and antimicrobial susceptibility following the introduction of the pneumococcal is insufficient. Also the data on pneumonia caused by other bacterial pathogen is insufficient.

M. pneumoniae is also a major infectious age group for children in kindergarten and school age, and it continues to be prevalent every three to four years. ${ }^{8}$ According to an epidemiological survey conducted by the National Institute of Health at the Korea Centers for Disease Control and Prevention (KCDC), the incidence of mycoplasma infection increased in 2007 and the incidence rate soared from 2010 to $2011 .{ }^{9} \mathrm{M}$. pneumoniae is often accompanied by pleural fluid and shows lobar pneumonia, which is difficult to differentiate with bacterial pneumonia by referring to on clinical patterns and chest radiologic findings. Recently, macroide-resistant M. pneumoniae in Korea has been reported, and it is necessary to find out the nationwide status of the disease, the effectiveness of antibiotic treatment, and the degree of resistance.

There have been reports of the distribution of pathogens, epidemic trends and antibiotic resistance of bacterial pathogens to respiratory infections in adults, but there have been no nationwide reports in children and adolescents in Korea. In particular, CAP in children and adolescents accounts for more than $50 \%$ of all ages, and the pathogen of pneumonia is different from that of adults, and the recent vaccination has resulted changes in pathogens. For this reason, national study is needed to analyze the prevalence, epidemical characteristics and pathogen of pneumonia in children and adolescents. Therefore, the purpose of this study is to establish monitoring network for CAP among children in connection with community-based cooperative hospitals and the KCDC. In addition, it is to study distribution of pathogens, epidemic trends of CAP and antibiotic usage and resistance of bacterial pathogens.

\section{Methods}

\section{Patients and study design}

A prospective study was conducted in patients under 18 years old, attended to hospital with the diagnosis of CAP. Patients who fulfilled the selection criteria were studied from August 2018 to May 2019 (first research period) and from August 2019 to June 2020 (second research period). The cooperative hospital monitoring network was established for the second and tertiary hospitals in six metropolitan areas (Seoul, Gyeonggi Provinces, Chungchong Provinces, Gangwon Provinces, Jeolla Provinces, Gyeongsang Provinces). From August 2018 to May 2019, 27 hospitals participated and from August 2019 to June 2020, 28 hospitals participated. The Korean Childhood Community Acquired Pneumonia Study Group; KoC-CAPS was established and this network represented laboratory monitoring networks where data of pneumonia can be collected, managed and analyzed in conjunction with each other and information can be shared (Additional file 1). 


\section{Inclusion criteria}

Among patients who have had a cough or a severe fever as a major symptom, patients diagnosed with pneumonia in the chest $\mathrm{X}$-ray were included during the study period. However, it was defined as a child under 18 years of age who had no history of using antibiotics within five days of the visit period.

\section{Exclusion criteria}

The upper respiratory tract infected patients, which is accompanied by rhinitis symptoms such as runny nose and stuffy nose, patients who had chronic underlying diseases or immune suppresive disease, and patients with a history of antibiotic use within five days were excluded.

\section{Study participants}

For each patient, a questionnaire with clinical and epidemiological features were completed. The questionnaire applied includes the following information: patients information (age, birth date, gender, name of hospital, specimen type, history of hospitalization, underlying disease, status of vaccination, siblings, clinical information (fever, cough, sputum, rhinorrhea, vomiting, sore throat, etc, radiologic findings, vital signs, breathing sound, $\mathrm{O}_{2}$ saturation), treatment (prescribed antibiotics, hospitalization period, sequelae) (Additional file 2).

\section{Collection of samples}

Samples were obtained from sputum, bronchoalveolar lavage, nasopharyngeal aspiration, or nasopharyngeal swab. Nasopharyngeal aspirates were obtained within 24 hours after enrollment. A suction catheter was used to passed through the nose into the lower part of the pharynx. A total $2 \mathrm{ml}$ nasopharyngeal aspirates was obtained and sent to laboratory for analysis within 48 hours. Nasal swab was obtained by inserting a swab into both nostrils parallel to the pallate. Throat swab was obtained from the posterial pharyngeal and tonsillar areas. Sputum or bronchoalveolar lavage specimens were also collected if possible. Culture for bacterial pathogens (S. pneumoniae, H. influenzae, S. aureus, K. pneumoniae, P. aeruginosa) and antimicrobial susceptibility test were performed. And atypical pneumonia pathogen (M. pneumoniae, C. pneumoniae, B. pertussis) were identified using polemerase chain reaction (PCR) test and culture. Virus (Respiratory syncytial virus (RSV) A, B, Influenza virus (IFV) A, B, Parainfluenza virus (PIV) 1, 2, 3, 4, Adenovirus (ADV), Human Rhinovirus (HRV), Human metapneumovirus (HMPV), Coronovirus (CoV) 229E, NL63, OC43, Bocavirus (BoV), Human Enterovirus (HEV)) were examined using multiplex PCR method.

\section{The detection of pathogen}

\section{A bacterial pathogen}

A bacterial pathogens were detected by culture, and cultured pathogens were perfomed antimicrobial susceptibility test. If the final identification of the bacteria is ambiguous or requires accurate identification, we confirmed the results by using Vitekll (Biomerieux, Hazelwood, USA) to verify the infection and 16S rRNA test was performed.

\section{Atypical pneumonia pathogen}

Atypical pneumonia pathogen was detected by PCR method. Nucleic acid was extracted from a total volume of $1 \mathrm{ml}$ of sample and purified. The cyclic Temperature settings were $94^{\circ} \mathrm{C} 20 \mathrm{sec}, 58^{\circ} \mathrm{C} 20 \mathrm{sec}, 72{ }^{\circ} \mathrm{C} 20 \mathrm{sec}$ amplified by 35 cycles with the last $72{ }^{\circ} \mathrm{C} 7 \mathrm{~min}$. And M. pneumoniae, $\mathrm{C}$. pneumoniae and B. pertussis were confirmed by using Allplex ${ }^{\mathrm{TM}}$ PneumoBacter Assay (Seegene, Seoul, South Korea).

\section{A viral pathogen}

For the multiplex RT-PCR, viral genomic RNA and DNA were extracted from a total volume of 1 ul of sample by the guanidinium thiocyanate extraction method. The lysis buffer included 500 molecules of the cloned amplified product used as internal control in each reaction tube and then excluded false negative results. Three independent multiplex reverse transcription nested RT-PCT assays able to detect from 1 to 10 copies of viral genomes were performed. One nested RT-PCR was performed using specific primer for PIV $(1,2,3,4)$, ADV, HEV, HMPV and another nested RT-PCR was prepared with specific primers for HRV (A, B, C), CoV (229E, NL63, OC43), BoV (1, 2, 3, 4) and third nested RT-PCR was using specific primer for RSV (A, B), IFV (A, B, subtype H1, H3, H1 pdm09) by using Allplex ${ }^{\mathrm{TM}}$ Respiratory Panel (Seegene, Seoul, South Korea).

\section{The susceptibility test of antibiotics}

In this study, the antibiotic susceptibility test of isolated bacteria measures minimum inhibitory concentration (MIC) using MicroScanR Microbiology System (Dade Behring, Tokyo, Japan) The criteria for judging antibioitics resistance follow the criteria of the Clinical Laboratory Standard Institute (CLSI).

\section{Results}

\section{Demographic results}

A total 1023 patients under 18 years old with the diagnosis of CAP were studied. Mean ages were $4.9 \pm 3.4$ (years, mean \pm standard deviation, range: 1 month-18 years). Most patients were between 1 and 3 years old $(309,30.2 \%)$ followed by the children between 7 and 11 years old (271, $26.5 \%)$, between 4 and 6 years old $(215,21 \%)$, under 12 month $(147,14.4 \%)$, over 12 years old $(72,7 \%)$. There were 9 cases in which age entries were omitted. There were 535 cases for male (52.3\%), 483 cases for female (47.2\%). There were five cases in which the gender was unknown. Regionally, 14 were reported in Gangwon province, 215 in Kyoungki, 360 in Kyoungsang, 114 in Seoul, 101 in Jeonla, and 219 in Chungcheong. 
Of 1,023 people, 973 (95.1\%) were hospitalized and 45 (4.3\%) were treated in outpatient clinics. There were 5 cases in which hospitalization was unknown. The mean hospital day for 932 people, whose hospitalization period is specified, was 6.8 days (range 1-47 days)

The specimen were collected from $12(0.2 \%)$ in BAL, 727 (71.1\%) in nasopharyngeal aspirate, $73(7.1 \%)$ in nasal swab, 195 (19.1\%) in sputum, $8(0.8 \%)$ in throat swab, $2(0.2 \%)$ in transtracheal aspirate. Most frequent symptoms were cough (93.3\%), fever (86.1\%), sputum (78\%), and rhinorrhea (51.1\%). Most frequent physical examination were rale (65\%), wheezing (19.5\%), decreased aeration (10.5\%) and hypoxia $(5.2 \%)$

Among the radiological findings of pneumonia, peribronchial infiltration was the most common (44.4\%), followed by lobar infiltration (42.8\%), interstitial infiltration (11.1\%), and pleural effusion (3.8\%). There were 212 patients with underlying disease, of them 79 had allergic disease, 14 had heart disease, 4 had kidney disease, 4 had endocrine disease, and 2 had cerebrovascular disease. Other accompanying diseases include neurological disorders, Down syndrome, and developmental delays etc. The antibiotics prescription rate was 939 (91.8\%), and of them macrolide prescription rate was the highest (69.6\%), followed by cephalosporin (40.8\%), and penicillin (27.1\%). The characteristics of the study population are depicted in Table 1.

Table 1. Demographic and clinical features of the study population

\begin{tabular}{|c|c|c|c|c|c|}
\hline Mean Age $\pm S D$ & $4.9 \pm 3.4$ & Clinical findings & $N(\%)$ & Physical examinations & $\mathrm{N}(\%)$ \\
\hline Age range (min-max) & $1 \mathrm{mo}-18 \mathrm{yrs}$ & Cough & $992(93.8)$ & Rale & $688(65)$ \\
\hline Age & $N(\%)$ & Fever & $911(86.1)$ & Wheezing & $206(19.5)$ \\
\hline$<12$ month & $147(14.4)$ & Sputum & $825(78)$ & Decreased airation & $111(10.5)$ \\
\hline $1-3 \mathrm{yrs}$ & $309(30.2)$ & Rhinorrhea & $541(51.1)$ & Hypoxia $<95 \%$ & $55(5.2)$ \\
\hline $4-6$ yrs & $215(21)$ & Poor oral intake & $137(12.9)$ & Chest retraction & $50(4.7)$ \\
\hline 7-11 yrs & $271(26.5)$ & Chill & $86(8.1)$ & Prescribed antibiotics & $\mathrm{N}(\%)$ \\
\hline$\geqq 12$ yrs & $72(7)$ & Sore throat & $86(8.1)$ & Macrolide & $654(69.6)$ \\
\hline Unknown & $9(0.9)$ & Dyspnea & $58(5.5)$ & Cephalosporin & $383(40.8)$ \\
\hline Total & 1023 & GI symptom & & Penicillin series & $254(27.1)$ \\
\hline Gender & $\mathrm{N}(\%)$ & Vomiting & $70(6.6)$ & Tetracyclin & $59(6.3)$ \\
\hline Male & $535(52.3)$ & Diarrhea & $37(3.5)$ & Semipenicillin lactamase inhibitor & $58(6.2)$ \\
\hline Female & $483(47.2)$ & Abdominal pain & $34(3.2)$ & Quinolone & $39(4.2)$ \\
\hline Place of Treatment & $N(\%)$ & Myalgia & $36(3.4)$ & Aminoglycoside & $5(0.5)$ \\
\hline Hospitalized & $973(95.1)$ & Chest pain & $21(2)$ & Vancomycin & $3(0.3)$ \\
\hline Outpatient clinic & $45(4.3)$ & Hoarseness & $17(1.6)$ & Lincomycin & $3(0.3)$ \\
\hline Species of sample & $N(\%)$ & Rash & $11(1)$ & Total & 939 \\
\hline Nasopharyngeal aspirates & $727(71.1)$ & Hemoptysis & $5(0.5)$ & & \\
\hline Sputum & $195(19.1)$ & \multicolumn{2}{|l|}{ Chest X-ray finding } & \multicolumn{2}{|l|}{$N(\%)$} \\
\hline Nasal swab & $73(7.1)$ & \multicolumn{2}{|c|}{ Peribronchial infiltlation } & \multicolumn{2}{|l|}{$470(44.4)$} \\
\hline Bronchoalveolar lavage & $12(1.2)$ & \multicolumn{2}{|l|}{ Lobar infiltlation } & \multicolumn{2}{|l|}{$453(42.8)$} \\
\hline Throat swab & $8(0.8)$ & \multicolumn{2}{|c|}{ Interstitial infiltlation } & \multicolumn{2}{|l|}{$117(11.1)$} \\
\hline Transtracheal aspirate & $2(0.2)$ & \multicolumn{2}{|l|}{ Pleural effusion } & \multicolumn{2}{|l|}{$40(3.8)$} \\
\hline
\end{tabular}

Abbreivations: N number, SD standard deviation, mo months, yrs years,

\section{Respiratory pathogens}

Of 1023 cases, the bacterial pathogen was identifiable in 264 cases (25.8\%) by culture, atpical pneumonia pathogen in 432 cases (42.2\%) by PCR test. The bacterial pathogens with isolated strains by cultures were as follows. S. aureus was 131 cases (12.8\%), S. pneumoniae 92 (9 \%), H. influenzae 20 (2 \%), P. aeruginosa 13 cases $(1.3 \%)$, and $K$. pneumoniae 8 cases ( $0.8 \%$ ). Of atypical pneumonia pathogen, there were 422 cases (97.7\%) for M. pneumoniae, 5 cases (1.2\%) for C. pneumoniae, and 5 cases $(1.2 \%)$ for B. pertussis.

1023 samples of CAP were tested virus PCR and the rate of positive for respiratory viruses was $65.7 \%$. HRV was most highest with 312 ( $29.8 \%$ ) followed by RSV (A+B) 212 (20.3\%), ADV 123 (11.8\%), IFV (A+B) 102 (9.8\%), HMPV 81 (7.7\%) CoV (OC43+NL63+2229E) 69 (6.6 \%) PIV(1+2+3+4) 67 (6.4 \%), BoV 51 (45.9 $\%)$, and HEV $30(2.9 \%)$. The frequency order of viruses was different slightly when comparing the results of the first and second research periods. The frequency of virus detection changed from the third place, which was ADV, IFV, CoV, HEV, PIV, MPV and BoV in second period and MPV, ADV, PIV, BoV, IFV, CoV and HEV in first period (Figure 1). 
M. pneumoniae was the most common bacteral pathogen which showed surge infection from August 2019 to December 2019 followed by S. aureus and S. pneumoniae. Bacterial CAP ended up abruptly from March 2020 when COVID19 had started. In contrast to bacterial pathogen, respiratory viruses showed seasonal pattern: RSV was detected mostly from November to January, ADV showed biphasic peak in November and April, HMPV in April and May, HRV dual peak in spring and autumn season, and BoV in April. All of the viruses were rarely detected after COVID19 outbreak (Figure 2).

\section{Results of respiratory pathogens according to age}

Respiratory viruses were the most common pathogen of CAP under the age of 3 years. Rate of viruses and M. pneumoniae was similar at the age of 4-6 years. From 7 years of age, bacteria was predominant for CAP; M. pneumoniae was the most common bacterial pathogen, followed by $S$. aureus. Interestingly, incidence of $S$. pneumoniae was more common than $S$. aureus only at the age of 1-3 years.

According to the positive rate of M. pneumoniae by age, the positive rate was highest at at age 7 to 11 (179 cases), followed at age 4 to 6 ( 121 cases), at age 1 to 3 (56 cases), at age 12 years of age and older (48 cases) and at less than 12 months ( 14 cases). Five cases of $C$. pneumoniae were detected at $7-11$ years of age. Five cases of $B$. pertussis were detected at the age of 1-3 in three cases and 7-11 in two cases. When comparing the virus detection rate by age, the positive rate was the highest among those under 12 months, followed by those aged 1-3 and 4-6 and 7-11 and 12 or older. (Table 2)

Table 2. Results of respiratory pathogen according to Age

\begin{tabular}{|llllllll|}
\hline & $<12 \mathrm{mo}$ & $1-3 \mathrm{yrs}$ & $4-6 \mathrm{yrs}$ & $7-11 \mathrm{yrs}$ & $\geqq 12 \mathrm{yrs}$ & UK & Total \\
\hline N of sample & 147 & 309 & 215 & 270 & 73 & 5 & 1023 \\
\hline Viruses & $127(86.4)$ & $262(84.8)$ & $136(63.3)$ & $111(41.1)$ & $24(30.8)$ & 1 & $661(64.5)$ \\
\hline M. pneumoniae & $14(9.5)$ & $56(18.1)$ & $121(56.3)$ & $179(66.3)$ & $48(65.8)$ & 3 & $422(41.3)$ \\
\hline S. aureus & $26(17.7)$ & $24(7.8)$ & $24(11.1)$ & $42(15.6)$ & $14(19.2)$ & 1 & $131(12.8)$ \\
\hline S. pneumoniae & $24(16.3)$ & $45(14.6)$ & $12(5.6)$ & $7(2.6)$ & $4(5.5)$ & $92(9)$ \\
\hline H. influenzae & $1(0.7)$ & $11(3.6)$ & $4(1.9)$ & $4(1.5)$ & & $20(2)$ \\
\hline P. aeruginosa & $3(2)$ & $3(1)$ & $3(1.4)$ & $3(1.1)$ & $1(1.4)$ & $13(1.3)$ \\
\hline K. pneumoniae & $3(2)$ & $1(0.3)$ & $2(0.9)$ & $2(0.7)$ & & $8(0.8)$ \\
\hline C. pneumoniae & & & & $5(1.9)$ & & $5(0.5)$ \\
\hline B. pertussis & $2(1.4)$ & $1(0.3)$ & $1(0.5)$ & $1(0.4)$ & & $5(0.5)$ \\
\hline
\end{tabular}

Abbreivations: N number, mo months, yrs years, UK unknown

\section{Results of mixed infection}

The proportion of mixed infection was $49.2 \%$, and the overall rate of mixed infection was hightest in virus/bacteria co-infection (15.6\%) followed by virus/atypical pneumonia pathogens (15\%) and virus/virus (10.6\%). We analyzed the rate of mixed infection in each study period. In first study period, mixed infection of virus/bacteria co-infection (20\%) was the highest was the highest, however in second study period, when mycoplasma pneumonia epidemics occured, mixed infection of virus/atypical pneumonia pathegen was highest (24.1\%) (Figure 3).

\section{Resistance of Antibiotics}

We assessed the antibiotics resistance rate of bacteria. A total of 92 cases $S$. pneumonia, $14.1 \%$ were resistant to penicillin, $8.7 \%$ to cefotaxime and ceftriaxone, $97.8 \%$ to cefaclor, $93.5 \%$ to erythromycin, $92.4 \%$ to azythromycin, $79.3 \%$ to tetracycline, and $72.8 \%$ to clindamycin. Of $21 \mathrm{cases}$ of $\mathrm{H}$. influenzae, $71.4 \%$ were resistant to ampicillin, $38.1 \%$ to amoxicillin/K clavulanate, and $28.4 \%$ to trimethoprim/sulfamethoxazole. Of the 131 cases $S$. aureus, $94.7 \%$ and $93.9 \%$ were resistant to penicillin and ampicillin, respectively, $53.4 \%$ to oxacillin, $48.1 \%$ to erythromycin, $43.5 \%$ to clindamycin, and no strains were resistant to trimethoprim/Sulfamethoxazole, teicoplanin, linezolid and vancomycin. All of the $8 \mathrm{~K}$. pneumoiniae cases showed resistance to ampicillin and cefazolin. Of 13 cases of $P$. aeruginosa, $7.7 \%$ were resistant to amikacin, cefepime, piperacillin and ceftazidime (Figure 4).

\section{Discussion}

Most of the studies about the causative agents of CAP in children are limited by the difficulty of obtaining adequate specimens. This study is meaningful in that it was the first prospective extensive study investigating respiratory pathogen of children with CAP at Korea. In this study, the rate of pathogen detection in children with CAP was $70.5 \%$. There are studies about the causative agent of CAP in many countries. In Taiwan study, at least one pathogen was identified in $68.3 \%$ of children with CAP, ${ }^{10}$ in China study, causative pathogen was identified in $70.1 \%$ of the hospitalized children with CAP at one hospital. ${ }^{11}$ In a US study of 3 years, causative pathogen was identified in $81 \%$ of patients under the age of 18 hospitalized with CAP. ${ }^{2}$ In study of Finland, $85 \%$ was detected in hospitalized children with pneumonia. ${ }^{12}$ The difference in detection rate in each country seems to be due to the difference in sample types and methods. The sample types collected in this study were nasopharyngeal swab/aspirate and sputum, and the causative pathogens were identified through PCR and culture. To detect viruses, the same method (PCR test) is used through nasopharyngeal swab/aspirate in other countries. However, unlike this study, most tests for 
bacterial detection were conducted through blood and pleural fluid culture, or blood PCR tests. As a result, it is thought that detection rate of the pathogen in each study is different. There are few studies about the causative agent of children with CAP in Korea. In 2009 , respiratory viruses were identified in $49.6 \%$ of severe lower respiratory tract infection in child. ${ }^{13}$ But unlike our study,there was no data for bacteria. Recently, there was also a study on the seasonal pattern in etiologic virus and M. pneumoniae in children hospitalized with CAP in Korea, which showed M. pneumoniae was the most common identified with pathogen. ${ }^{14}$ It was noticeable that bacterial pathogens as well as viruses were also tested. In general, common bacterial pathogens of CAP in children are $S$. pneumoniae, $H$. influenzae, $S$. aureus. To differentiate true pathogen from colonization in CAP, culture from blood/pleural fluid sample or urinary $S$. pneumoniae antigens test using immunochromatography is better than nasopharyngeal sample. ${ }^{1,12}$ In current study, we did not use this method and used bacterial culture or PCR from nasopharyngeal swab/aspirates. However, detection rate of bacteria from blood culture in CAP is very low and pleural culture is limited to only children with parapneumonic effusion. It is difficult to determine these bacterias as the causative pathogen in sample of nasopharyngeal swab/aspirate. S. pneumoniae and $\mathrm{H}$. influenzae are common flora in upper respiratory tract and up to two-thirds of children younger than 5 years are colonized with common bacterial pathogens in the upper respiratory tract. Identification of bacteria from the upper respiratory tract does not always mean pathogen of CAP, therefore physicians should consider clinical relevance for ascertaining bacterial etiologies of pneumonia. ${ }^{15}$

Over the past 20 years, more than 20 cases of $B$. pertussis have been reported every year in Korea. During 2001-2008, an average of 11.5 cases of $B$. pertussis per year, ${ }^{16}$ and it was reported a gradual increase from 2009 to $2012 .{ }^{17}$ In particular, $24.5 \%$ of Korean adolescents and adults with chronic cough were positive against $B$. pertussis in $2015 .{ }^{18}$ Due to the lack of data on B. pertussis in pediatric age in Korea, it was important to obtain epidemiological data on $B$. pertussis through the results of the surveillance network study. In this study, B. pertussis was isolated from five children, which was less than we expected. All were found between January and April and with two of them were younger than three months old, while the other three were aged one, six and nine years old. Due to the National Immunization Program by Korean government, incidence of $B$. pertussis is low in children, but gradual increase in adolescents and adults requires the need for booster injection. Based on this data, it will be necessary to accumulate various epidemiological data on pertussis through the construction of a continuous monitoring network in children and adolescents in Korea. The common pathogens of CAP in adults were $S$. pneumoniae, K. pneumoniae, and P. aeruginosa, in a prospective multicenter study in Korea, while S. pneumoniae, M. pneumoniae, K pneumoniae in other study. ${ }^{19,20}$ Unlike adults, the most common cause of CAP in children vary according to age. Several studies have previously reported that respiratory viruses are the leading cause of CAP, which can be detected in more than $50 \%$ of the cases. ${ }^{21,22}$ However, this results may vary by studies and age groups. Similar to our research, in Peru study of patients who were hospitalized for pneumonia under the age of 18, M. pneumoniae was more frequently detected than respiratory viruses. ${ }^{23}$ Meanwhile in Taiwan study, S. pneumoniae was the most common pathogen, than any other pathogens, and the detection rate of pneumococcus was much higher than in our study. ${ }^{10}$ This may attribute to relatively lower vaccination rates in Taiwan and Korean government has started pneumococcal vaccination to every infants and children as National Immunization Program since 2014, which may rapidly decrease the frequency of $S$. pneumoniae pneumonia. ${ }^{7}$

Rate of M. pneumoniae had surged from the fall of 2019, which abruptly ended after COVID19 outbreak in 2020. M. pneumoniae is a major pathogen of CAP in children and adolescents. ${ }^{24}$ Recent study showed that mycoplasma was responsible for about $20-30 \%$ of CAP at the age of three to four years, and during the epidemic, M. pneumoniae infected even children of 2 years old. ${ }^{6,24,25}$ M. pneumoniae pneumonia epidemics occur every 3-5 years. ${ }^{24,26,27}$ It was reported that epidemics of M. pneumoniae pneumonia occurred in 2007, 2011, and $2015 .{ }^{28,29}$ According to the trend cycle, the results of this study confirmed that the mycoplasma epidemic has been re-floating in 2019. Interestingly, rate of $M$. pneumoniae decreased abruptly after COVID 19. This may attribute to social distancing, mask wearing, hand washing, and online schooling.

The seasonal difference in detection rates for viruses is consistent with the existing data. We found that the respiratory viruses composed of major pathogen for CAP in young children under the age of 3 years. It is known that viruses may cause pneumonia, either directly or by rendering the host more susceptible to bacterial infection. ${ }^{11}$ In studies of CAP in childen, mixed infections were identified in $34-41 \%$ of child with CAP, and mixed viral-bacterial infection showed highest rate. ${ }^{11,30-32}$ On the other hand, two US studies have reported lower rate (23-26\%) of mixed infection..$^{2,31}$ In this study, the proportion of mixed infection was $49.2 \%$, which was higher than in previous studies. The mixed infection of virus, bacteria and atypical bacterial pathogen were $3.6 \%$. It is assumed that the difference of coinfection rate and pattern of coinfection may be related to seasonal, geographical and racial factors. And it may also vary depending on the type of sample or laboratory testing method.

Although viruses area a major cause of childhood CAP, a majority of children with pneumonia receive antibiotics. Empiric use of antibiotics remains as cornerstone of treatment in the absence of results in causative agent of pneumonia. In the U.S. guidelines, amoxillin is used in previously healthy outpatients who have been properly vaccinated if they suspect mild and moderate bacterial pneumonia. And it is recommended to use macrolides if the CAP caused by atypical pneumonia pathogen is suspicious. ${ }^{33}$ In our study, empiric antibiotics prescription rate was high, and of them, macrolide prescription rate was the highest. The high macrolide prescription rate may be attributable to the epidemics of M. pneumoniae in 2019.

The rate of antibiotics resistance in this study showed similar results as previous reports. Penicillin sensitivity of pneumococcus in the study of adult pneumonia was $42.9 \%$ in 2001 , but 100 percent in the $2010 .{ }^{19,20}$ According to treatment guideline of CAP, S. pneumoniae has a low resistance rate for the penicillin and quinolone and relatively high resistance rate for some cephalosporin and macrolide. ${ }^{34}$ Our results also showed high resistance rates for secondgeneration cephalosporin and macrolide, while low resistance rates for the third-generation cephalosporin, penicillin, and quinolone, which is similar to what was previously reported. In addition, the results of the antibiotic resistance of $H$. influenzae, $P$. aeruginosa, $K$. Pneumoniae, $S$. aureus were also confirmed to be similar to the 2017 National Antibacterial Resistance Survey Report. ${ }^{35}$ These data can be helpful in forming the basis of empiric antibiotics therapy in child with CAP.

\section{Study Limitations}


There were some limitations of this study. First, we could not differentiate true pathogen from normal flora, because we mostly collected samples from upper respiratory tract. Due to the difficulty in collecting sputum from lower respiratory tract in young children, this may remain as limitation in children. Secondly, even though this was nationwide multi-center study, number of samples was relatively lower than expected, especially in outpatient clinic. The number of samples decreased from February 2000. This is the beginning of COVID19 epidemic, and is affected by the decrease in respiratory infections, including children and adolescents, as well as adults, and the disappearance of respiratory viruses. In particular, since February 2020 , the number of pneumonia patients has decreased sharply due to the restriction of group activities such as highintensity social distance, the use of masks and hand washing. Also the indefinite postponement of opening at kindergarten and schools, and home classes has also been an important factor in the decrease in infection. Third, laboratory results such as white blood cell count or C-reactive protein were not investigated. In the future, it is required to match pathogens with clinical symptoms.

\section{Conclusions}

This study established surveillance network for monitoring of respiratory infections in Korean children. This research provided scientific evidence of policies for managing pneumonia of children and adolescents in Korea by identifying trends in the prevalence of pathogens in children and adolescents with CAP. It will also contribute to the analysis of antibiotic resistance status for bacteria and proper treatment guidelines for children's respiratory infections in Korea. In addition, this nationwide network system can help searching for a novel pathogen and monitoring of new respiratory infections such as COVID19, and provide with early national strategies in preparation for a new epidemic.

\section{Abbreviations}

CAP; community-acquired pneumonia, KCDC; Korea Centers for Disease Control and Prevention, PCR; polemerase chain reaction, MIC; minimum inhibitory concentration, HRV; Human Rhinovirus, RSV; Respiratory syncytial virus, IFV; Influenza virus, PIV; Parainfluenza virus, ADV; Adenovirus, HMPV; Human metapneumovirus, CoV; Coronovirus, BoV; Bocavirus, HEV; Human Enterovirus, Hib; Hemophilus influenzae type B, PCV; pneumococcal conjugate vaccine, N number, SD; standard deviation, mo; months, yrs; years.

\section{Declarations}

\section{Acknowledgements}

Not applicable

\section{Authors' contributions}

JYS and EHC designed the conceptualization and experiments. EJR, MHL, JYL, HBK, YMA, JKK, HYK, MJK, EKK, EAY, SJL, YP, UHS, EL, ESY, HMC, MYS, HLC, YYJ, BSC, JAJ, STY, MSS, JTK, BSK, YHW, SJY, HJY, MYH, and HYY carried out investication. EJR, and MHL performed data curation. EJR wrote the main manuscript text. ESL carried out data curation. EJR, MHL and ESL analyzed and interpreted the patient data KJW, DHK, and SUJ performed analsis and microbiologic detection. EJR, EHC, MHL and JYS approved the final manuscripts. All authors read and approved the final manuscript.

\section{Funding information}

This research was supported by a grant from the Korea Centers for Disease Control and Prevention, Republic of Korea (Grant Number:4800-4821-304)

This fund provides financial support in the investigation, desigh of the study, data collection, data analysis, and interpretation of data.

\section{Availability of data and materials}

The data were collected through the survillance system of Korean Childhood Community Acquired Pneumonia Study Group of Korean Academy of Pediatric Allergy and Respiratory Disease. Data are available from the corresponding authors on resonable request and with permission of Korean Academy of Pediatric Allergy and Respiratory Disease.

\section{Ethics approval and consent to participate}

This study was approved by the Institutional Review Board and Ethics Committee of Chungnam Nationl University Hospital. (IRB No 2019-07-037) The parents of all study participants gave written informed consent before study enrollment. All methods were performed in accordance with the relevant guidelines and regulations.

\section{Consent of publication}

Not applicable

\section{Author details}

${ }^{1}$ Department of Pediatrics, Chungnam National University Hospital, Daejeon, Republic of Korea. ${ }^{2}$ Department of Pediatrics, Incheon Medical Center, Incheon, Republic of Korea. ${ }^{3}$ Department of Pediatrics, Hallym University Hospital, Chuncheon, Republic of Korea. ${ }^{4}$ Department of Pediatrics, Inje Sanggye Baek Hospital, Seoul, Republic of Korea. ${ }^{5}$ Department of Pediatrics, Eulji University Hospital, Seoul, Republic of Korea. ${ }^{6}$ Department of Pediatrics, Kangwon University hospital, Chuncheon, Republic of Korea. ${ }^{7}$ Department of Pediatrics, Pusan University Yangsan Hospital, Yangsan, Republic of Korea. ${ }^{8}$ Department of 
Pediatrics, Sejong Chungnam University Hospital, Sejeong, Republic of Korea. ${ }^{9}$ Department of Pediatrics, Dongkuk University Ilsan Hospital, Ilsan, Republic of Korea. ${ }^{10}$ Department of Pediatrics, Daejeon's Saint Mary's Hospital, Daejeon, Republic of Korea. ${ }^{11}$ Department of Pediatrics, Eulji University Daejeon Hospital , Daejeon, Republic of Korea. ${ }^{12}$ Department of Pediatrics, Wonkwang University Sanbon Hospital, Sanbon, Republic of Korea. ${ }^{13}$ Department of Pediatrics, Dankook University Hospital, Cheonan, Republic of Korea. ${ }^{14}$ Department of Pediatrics, Cheonnam National University Hostpial, Kwangjoo, Republic of Korea.

${ }^{15}$ Department of Pediatrics, Chosun University Hostpial, Kwangjoo, Republic of Korea. ${ }^{16}$ Department of Pediatrics, Jesushospital, Jeonju, Republic of Korea.

${ }^{17}$ Department of Pediatrics, Soonchunhyang University Bucheon Hospital, Bucheon, Republic of Korea. ${ }^{18}$ Department of Pediatrics, Daegu Catholic University Hospital, Daegu, Republic of Korea. ${ }^{19}$ Department of Pediatrics, Kyungpook National University Hostpial, Daegu, Republic of Korea. ${ }^{20}$ Department of Pediatrics, Dong A University Hospital, Pusan, Republic of Korea. ${ }^{21}$ Department of Pediatrics, Wonkwang University Hospital, Iksan, Republic of Korea. ${ }^{22}$ Department of Pediatrics, Soonchunhyang University Hospital, Gumi, Republic of Korea. ${ }^{23}$ Department of Pediatrics, Uijeongbu Saint Mary's Hospital, Uijeongbu, Republic of Korea. ${ }^{24}$ Department of Pediatrics, Ganneung Asan Hostpital, Gangneung, Republic of Korea. ${ }^{25}$ Department of Pediatrics, Pusan ST. Mary's Hospital, Pusan, Republic of Korea. ${ }^{26}$ Department of Pediatrics, Kangbuk Samsung Hospital, Seoul, Republic of Korea. ${ }^{27}$ Department of Pediatrics, Soonchunhyang University Hospital, Seoul, Republic of Korea. ${ }^{28}$ Department of Pediatrics, Bundang CHA Medical Center, Seongnam, Republic of Korea.

${ }^{29}$ Department of Pediatrics, Kogel hostpial, Daejeon, Republic of Korea. ${ }^{30}$ Analysis of Bacteriolog, Korea Center For Disease and Prevention, Sejeong, Republic of Korea.

\section{References}

1. Kartz SE, Williams DJ. Pediatric communityacquired pneumonia in the United states. Changing epidemiology, diagnostic and therapeutic challenges and areas for future research. Infect Dis Clin $\mathrm{N}$ Ar 63.

2. Jain S, Williams DJ, Arnold SR Ampofo K, Bramley AM, Reed C, Stockmann C, Anderson EJ, Crijalva CG, Self WH, et al : Communityacquired pneumonia requiring hospitalization among U.S. children. New Engl J Med. 2015; 372:835-45.

3. Grace EL, Scott AH, Seth SC, Matthew PK, Samir SS. National hospitalization trends for pediatric pneumonia and associated complications. Pediatrics. 2010;126:204-13.

4. Ministry of Health and Welfare Press Release January 19th 2017. Available from: https://www.mohw.go.kr/react/al/sal0301vw.jsp? PAR_MENU_ID=04\&MENU_ID=0403\&CONT_SEQ=338168.

5. Korea National Statistical Office. Frequent diseases statistics of Healthcare big data open system in Health Insurance Review and Assessment Service. Available from: http://opendata.hira.or.kr/op/opc/olapHifrqSicklnfo.do.

6. Lee $\mathrm{CH}$, Won YK, Roh EJ, Suh DI, Chung EH : A nationwide study of children and adolescents with pneumonia who visited Emergency Department in South Pediatr. 2016;59(3):132-138 .

7. Black SB, Shinefield HR, Ling S, Hansen J, Fireman B, Spring D, Noyes J, Lewis E, Ray P, Lee J, et al.

Effectiveness of heptavalent pneumococcal conjugate vaccine in children younger than five years of age for prevention of pneumonia. Pediatr Infect Dis $\mathrm{J}$ $2002 ; 21: 810-5$.

8. Kim JW, Seo HK, Yew EK, Park SJ, Youn SH, Jeong HY, Han MY. Mycoplasma pneumoniae pneumonia in Korean children, from 1979 to 2006 -a metaanalysis. Korean J Pediat. 2009;52(3):315-23.

9. Kim SH, Jeong SO. Characteristics of Mycoplasma Respiratory Infection in Korea in 2011. Korea Centers for Disease and Prevention, Public health weekly report. 2011;4(49):893-6. Available from: http://kdca.go.kr/board/board.es?mid=a20602010000\&bid=0034\&act=view\&list_no=12990.

10. Chi H, Huang YC, Liu CC, Chang KY, Huang YC, Lin HS, Chang LY, Ho YH, Tsao KC, Mu JJ, et al. Characteristics and etiology of hospitalized pediatric community-acquired pneumonia in Taiwan. J Formos Med Assoc. 2020;119:1490-99.

11. Jiang W, Wu M, Zhou J, Wang Y, Hao C, Ji W, Zhang X, Gu W, Shao $X$. Etiologic spectrum and occurrence of coinfections in children hospitalized with communityacquired pneumonia. BMC Infectious Diseases. 2017;17:787-95.

12. Juven T, Mertsola J, Waris M, Leinonen M, Meurman O, Roivainen M, Roivainen M, Eskola J, Saikku P, Ruuskanen O. Etiology of community acquired pneumnonia in 254 hospitalized children. Pediatr Infect Dis J. 2000;19:293-8.

13. Chun JK, Lee JH, Kim HS, Cheong HM, Kim KS, Kang C, Kim DS. Establishing a surveillance network for severe lower respiratory tract infections in Korean i 4.

14. Lee E, Kim CH, Lee YJ, Kim HB, Kim BS, Kim HY, Kim YS, Kim SY, Park CR, Seo JH, et al. Annual and seasonal patterns in etiologies of pediatric community acquired pneumonia due to respiratory viruses and Mycoplasma pneumoniae req 42.

15. Abdullahi O, Nyiro J, Lewa P, Slack M, Scott JAG. The descriptive epidemiology of streptococcus pneumoniae and Haemophilus influenzae nasopharyngeal carriage in children and adults in Kilifi district, Kenya. Pediatr Infect Dis J. 2008;27(1):59-64.

16. Korea Centers for Disease Control and Prevention. Disease web statistics system Cheongju: Korea Centers for Disease Control and Prevention; 2016 [cited 2016 Dec 1]. Available from: http://is.cdc.go.kr/dstat/index.jsp.

17. Han YI, Choi JY, Lee H, Lee TJ. Active surveillance of pertussis in infants under 6 months of age: a single center experience form 2011 to 2013 . Korean J Pediatr Infect Dis. 2014;21:114-20. 
18. Lee SY, Han SB, Kang JH, Kim JS. Pertussis prevalence in Korean adolescents and adults with persistent cough. J Korean Med Sci. 2015;30:388-90.

19. Woo JH, Kang JM, Kim YS, Shin WS, Ryu JH, Choi JJH, Kim YR, Cheong HJ, Uh ST, Park DS, et al. A prospective multicenter study of communityacquired pneumonia in adults with emphasis on bacterial etiology. Korean J Infect Dis 2001:3 3:1-7.

20. Chong YP, Jung KS, Lee KH, Kim MN, Moon SM, Park S, Hur J, Kim DM, Jeon MH, Woo JH. The bacterial etiology of community acquired pneumonia in Korea: A nationwide prospective multicenter study. Infect Chemother. 2010;42:397403

21. Padilla YJ, Lindo PF, Rojas GR, Tantalean DFJ, Suarez MV, Cabezas SC, Morales de SGS, Hijar GG. Etiology of community acquired pneumonia in children 259 months old in two etiologically different communities from Peru. Arch Argent Pediatr. 2010;108(6):516-23.

22. Stuckey Schrock K, Hayes BL, Gerog C. Community acquired pneumonia in children. Am Farm Phys. 2012;86(7);661

23. Juana del VM, Wilmer SC, Angela CT, Fiorella OP, Eduardo V, Claudia U, Miguel AAL, Maria del D, Ronald NF, Monica EV, et al. Molecular etiological profile of atypical bacterial pathogens, viruses and coinfections among infants and children with community acquired pneumonia ac 94.

24. Eun BW, Kim NH, Choi EH, Lee HJ. Mycoplasma pneumonia in Korean children: The epidemiology of pneumonia over 8 year period. Journal of Infection. 21 31.

25. Kim EK, Youn YS, Rhim JW, Shin KS, Kang JH, Lee KY. Epidemiological comparison of three Mycoplasma pneumonia epidemics in a single hospital over 10 years. Korean J Pediatr. 2015;58:172-7.

26. Hauksdottir GS, Jonsson T, Sigurdardottir V, Love A. Seroepidemiology of Mycoplasma pneumonia infections in Iceland. 198795. Scand J Infect Dis. 1998;30:177-80.

27. Foy HM. Infections caused by Mycoplasma Pneumoniae and possible carrier state in different populations of patients. Clin Infect Dis. $1993 ; 17(1)$ S37-46.

28. Kim JH, Kim JY, Yoo CH, Seo WH, Yoo Y, Song DJ, Choung JT. Macrolide resistance and its impacts on M. pneumonia in children: comparison of two recen 6.

29. Wy HH, Min DOH, Kim DS, Park MS, Shim JW, Jung HL Shim JY. Clinical characteristics of Mycoplasam pneumoniae pneumonia in Korean children during the recent 3 epidemics. Allergy Asthma Respir Dis. 2017;5(1):8-14.

30. Chen CJ, Lin PY, Tsai MH, Huang CG, Tsao KC, Wong KS, Chang LY, Chiu CH, Lin TY,HuangYC.Etiology of community acquired pneumonia in hospitalized children in Northern Taiwan. Pediatr Infect Dis J. 2012;31:196-201.

31. Michelow IC, Olsen K, Lozano J, Rollins NK, Duffy LB, Ziegler T, Kauppila J, Leinonen M, McCracken GH. Epidemiology and clinical characteristics of community-acquired pneumonia in hospitalized children. Pediatrics 2004;113:701-7.

32. Tsolia Mn, Psarras S, Bossios A, Audi H, Paldanius M, Gourgiotis D, Kallergi K, Kafetzis DA, Constantopoulos A, Papadopoulos NG. Etiology of communityacquired pneumonia in hospitalized school-age children: evidence of high prevalence of viral infections. Clin Infect Dis. 2004;39:681-6.

33. Badley JS, Byington CL, Shah SS, Alverson B, Carter ER, Harrison C, Kaplan SL, Mace SE, McCracken Jr GH, Roore MR, et al. The management of communityacquired pneumonia in infants and children older than 3 months of age: clinical practice guidelines by the pediatric infectious diseases society and the inf 76.

34. Song JH, Jeong KS. Guideline for treatment of community-acquired pneumonia. J Korean Med Assoc. 2010;53(1):20-42.

35. Korea Centers for Disease and Prevention, Annual Report of the National Antimicrobial Resistance Survey 2017. Available from: http://www.kdca.go.kr/nohas/common/board/readBoardView.do

\section{Figures}




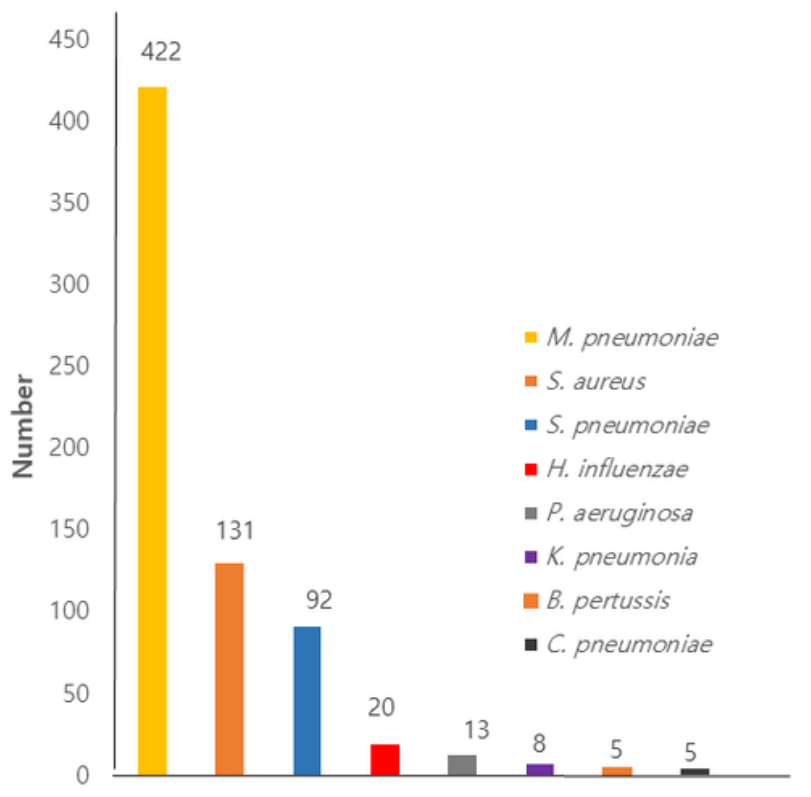

Bacterial pathogen

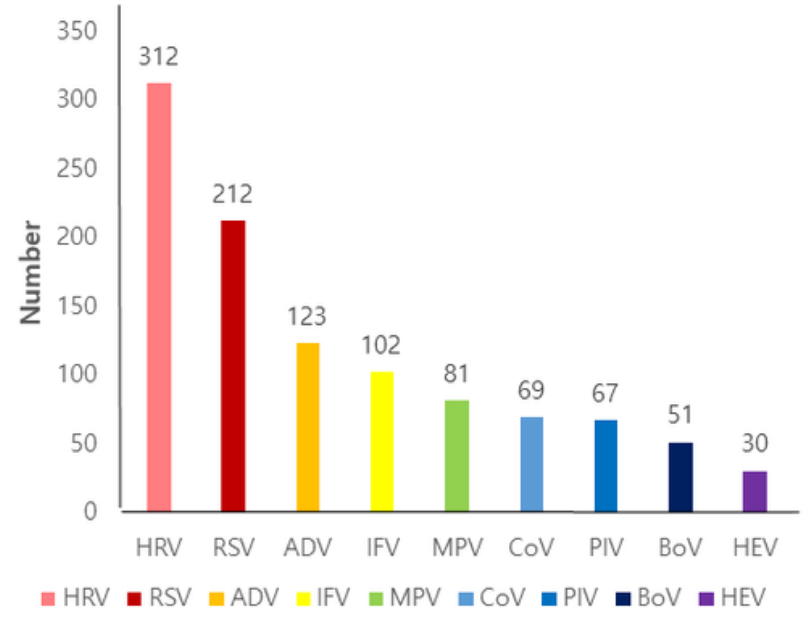

Viral pathogen

\section{Figure 1}

The number of detected respiratory pathogens. HRV, Human Rhinovirus; RSV, Respiratory syncytial virus; IFV, Influenza virus; PIV, Parainfluenza virus; ADV, Adenovirus; HMPV, Human metapneumovirus; CoV, Coronovirus; BoV, Bocavirus; HEV Human Enterovirus

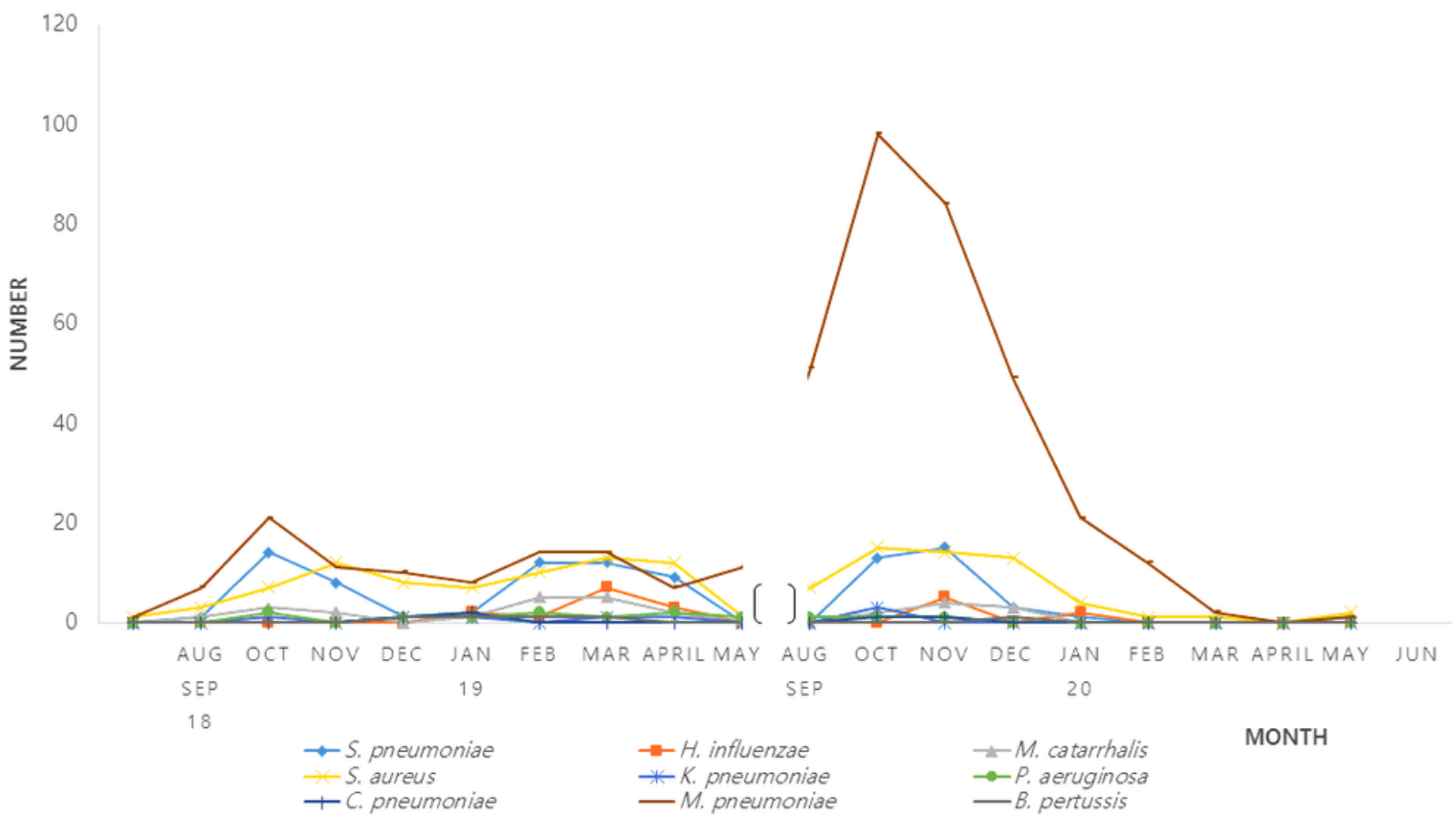

(A) The bacterial pathogens of CAP

Figure 2 
The annual and seasonal pattern of respiratory pathogen of CAP. (A) The respiratory bacterial pathogens (B) The respiratory viral pathogens. HRV, Human Rhinovirus; RSV, Respiratory syncytial virus; IFV, Influenza virus; PIV, Parainfluenza virus; ADV, Adenovirus; HMPV, Human metapneumovirus; CoV, Coronovirus; BoV, Bocavirus; HEV Human Enterovirus

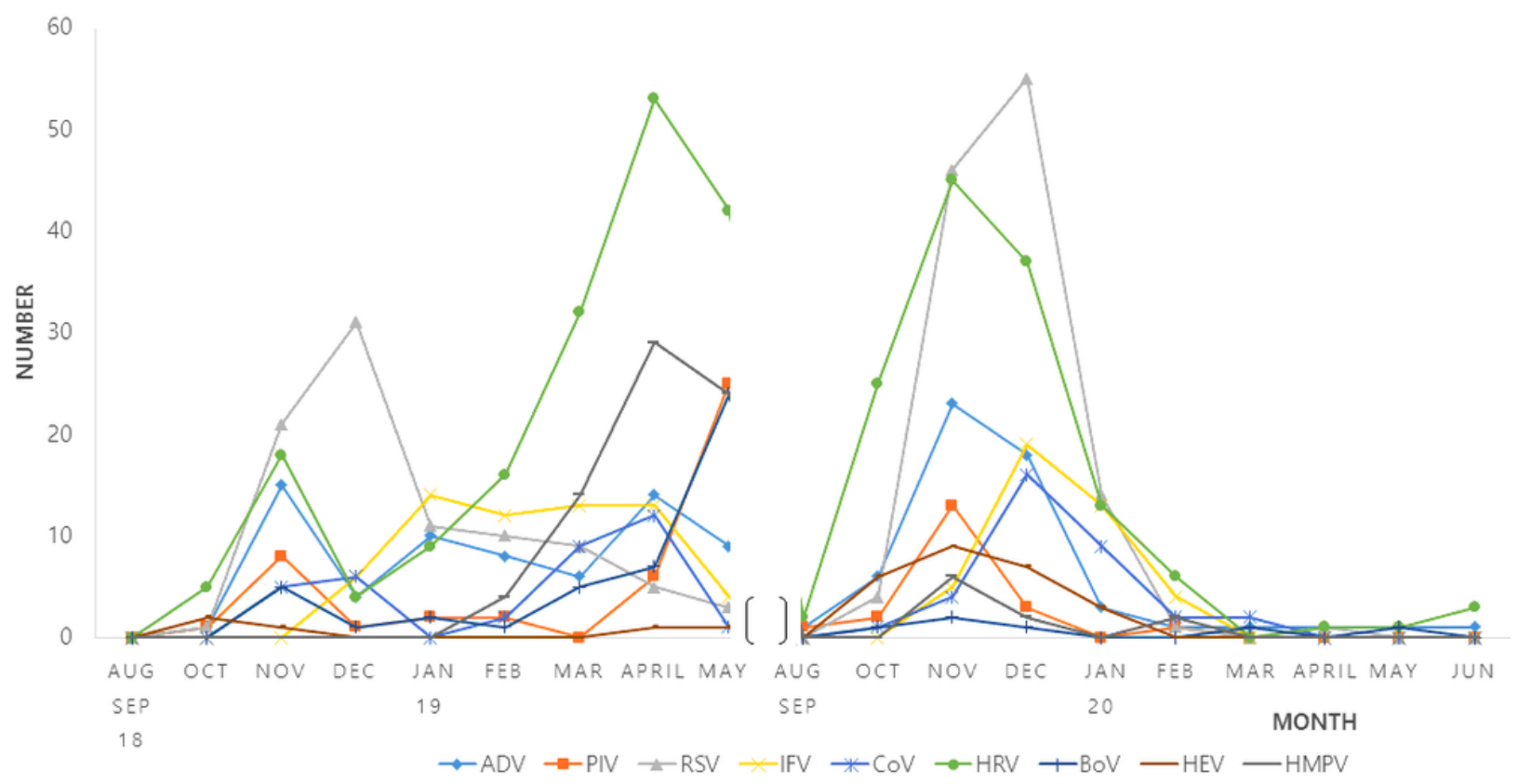

\section{(B) The respiratory viruses of CAP}

\section{Figure 3}

The percentage of mixed infection in CAP

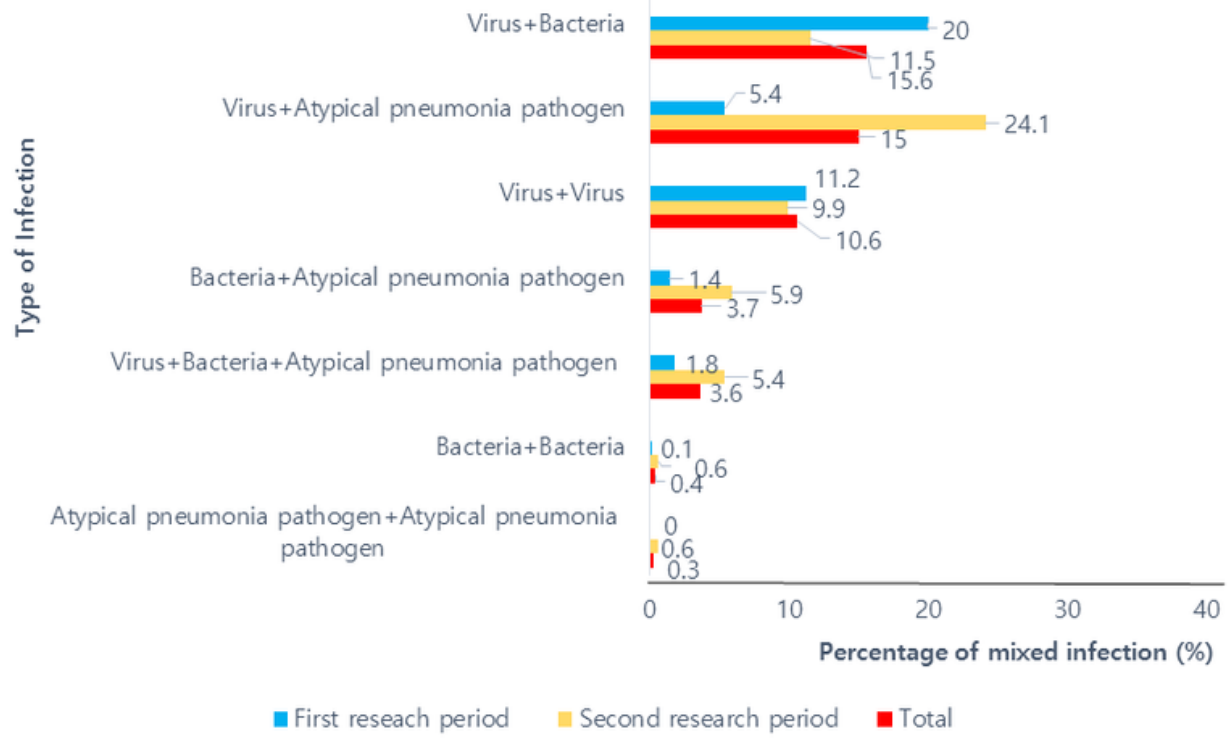


Figure 4

The percentage of resistance in antibiotics. (A) S. pneumoniae (B) S. aureus (C) H. influenzae (D) K. pneumoniae (E) P. aeruginosa

\section{Supplementary Files}

This is a list of supplementary files associated with this preprint. Click to download.

- additionalfile1.pdf

- additionalfile2.pdf 